\title{
RANCANGAN PERBAIKAN METODE KERJA DAN ALAT BANTU PADA STASIUN PENGISIAN BANTAL
}

\author{
Nukhe Andri SIlviana \\ Jurusan Teknik Industri Fakultas Teknik Universitas Medan Area, Medan, Indonesia \\ *Corresponding Author: nukheandri@staff.uma.ac.id
}

\begin{abstract}
Abstrak - PT. X adalah perusahaan yang bergerak di bidang tekstil untuk produksi: Padding, Bedding goods dan High Density Padding (HDP). Sebagian besar proses produksi di perusahaan ini dilakukan secara manual dengan posisi tubuh yang tidak ergonomis. Proses produksinya terdiri dari pembuatan perlengkapan tidur seperti bantal, guling dan kasur. Selain itu, perusahaan ini memproduksi sarung bantal dan perlengkapan tempat tidur. Penelitian ini bertujuan untuk memperbaiki metode dan fasilitas kerja untuk mengurangi keluhan muskuloskeletal dengan memperbaiki metode dan fasilitas kerja yang ada serta membuat SOP dengan menggunakan fasilitas baru berdasarkan data antropometri pekerja agar dapat menghemat waktu. dalam proses pengisian bantal. Tahapan yang digunakan untuk memperbaiki metode kerja guna mendeteksi keluhan muskuloskeletal menggunakan Standard Nordic Questionnaire, sedangkan metode REBA digunakan untuk menilai postur kerja. Hasil penilaian kondisi sebenarnya dari kedua metode yang ada dianalisis berdasarkan keluhan MSD yang terjadi, ketidaksesuaian ukuran fasilitas kerja dan antropometri pekerja, metode kerja. Gambaran kondisi eksisting yang diperoleh dianalisis dan dievaluasi sehingga dapat menghasilkan desain fasilitas kerja baru yang ergonomis sehingga metode kerja yang lebih baik. Perancangan fasilitas kerja berupa kursi kerja operator dan meja geser berdasarkan prinsip antropometri bertujuan untuk mengurangi keluhan pada kaki, pergelangan tangan, tangan dan leher. Sedangkan berdasarkan proses gang chart didapatkan hasil peningkatan produktivitas pada proses pengisian bantal. Dari hasil proses gang chart pekerja didapatkan pengurangan waktu tunda (idle) pada operator 3 dan 5 . Waktu proses pengisian bantal sebenarnya dilakukan sebanyak 25 kali, sehingga setelah perbaikan metode kerja dan fasilitas kerja dapat dilakukan 26 menjadi 27 kali. Berdasarkan perbaikan fasilitas kerja tersebut, diusulkan metode kerja standar baru berupa standar operasional prosedur (SOP) untuk proses pengisian bantal.
\end{abstract}

Kata Kunci: Musculoskeletal, Standard Nordic Quesionnaire, REBA, Pekerjaan repetitive.

\section{Pendahuluan}

Postur kurang ergonomis saat bekerja bersumber pada posisi kerja operator yang kurang nyaman, peralatan ataupun fasilitas kerja yang kurang memadai sehingga menimbulkan metode kerja yang kurang baik, efektif dan efisien. (Tarwaka, dkk. 2004) .

Pengertian efektif berkaitan dengan cara kerja yang tepat serta waktu penyelesaian pekerjaan yang singkat, sedangkan pengertian efisiensi berkaitan dengan meminimalkan biaya untuk menyelesaikan pekerjaan tersebut. Efektifitas dan efisiensi kerja tidak boleh mengabaikan kualitas dari produk yang dihasilkan. Dalam usaha mendapatkan metode kerja yang baik perlu dilakukan analisis terhadap metode kerja yang digunakan dan melakukan perbaikan metode kerja aktual yang mungkin belum menghasilkan produktifitas yang optimal. Analisa metode (Methods Analysis) adalah kegiatan pencatatan secara sistematis dan pemeriksaan dengan seksama mengenai cara yang berlaku atau diusulkan untuk melaksanakan cara kerja. Berdasarkan hasil penelitian yang pernah diteliti oleh Erlina M. dan Dienni N. Di PT XYZ. Dari Occupational Health Service PT XYZ didapatkan data hasil anamnesa ergonomi pekerja pada packaging line produk bumbu A, pabrik 1 yang menyatakan adanya keluhan sakit pada dimensi tubuh tangan kanan dan punggung yang memiliki persentase keparahan masing-masing sebesar $80 \%$ dan $66,67 \%$. Hal ini menyebabkan pekerja merasa tidak nyaman dalam melaksanakan pekerjaannya. Penelitian ini memberikan usulan metode kerja berupa keseimbangan gerak antara kedua belah tangan dan gerakan tangan pekerja dan 
rancangan tempat kerja yang disesuaikan dengan prinsip ergonomi.

Oleh karena itu, Untuk mengurangi keluhan MSDs maka diperlukan perbaikan metode kerja dan fasilitas kerja berupa alat bantu pada bagian pengisian bantal di PT. X.

Penelitian yang dilakukan di PT. X memiliki tujuan umum yaitu untuk melakukan perbaikan metode dan fasilitas kerja untuk mengurangi keluhan musculoskeletal dan juga pembuatan SOP dengan penggunaan fasilitas baru berdasarkan data antropometry pekerja agar dapat menghemat waktu proses pengisian bantal.

Sedangkan tujuan khusus dari penelitian ini antara lain:

1. Mengidentifikasi keluhan musculoskeletal yang dirasakan oleh operator pada saat bekerja.

2. Penilaian postur kerja operator dengan menggunakan metode REBA.

3. Melakukan pengukuran dimensi tubuh sebagai pedoman untuk perancangan fasilitas kerja yang dibutuhkan.

4. Memberi suatu usulan perbaikan terhadap metode kerja yang ada dan merancang fasilitas kerja berupa alat bantu untuk mereduksi keluhan musculoskeletal $\left(\mathrm{MSD}_{\mathrm{s}}\right)$ pekerja dalam melakukan pekerjaannya.

\section{Tinjauan Pustaka}

\section{Ergonomi}

Istilah ergonomi berasal dari bahasa Latin, yaitu Ergon (kerja) dan Nomos (hukum alam), jadi ergonomi dapat diartikan sebagai studi tentang aspek-aspek manusia dalam lingkungan kerjanya yang ditinjau secara anatomi, fisiologi, psikologi, engineering, manajemen dan desain atau perancangan untuk mendapatkan suasana kerja yang sesuai dengan manusianya.

Ergonomi adalah suatu cabang ilmu yang sistematis untuk memanfaatkan informasi-informasi mengenal sifat, kemampuan, dan keterbatasan manusia dalam merancang suatu sistem kerja sehingga orang dapat hidup dan bekerja pada sistem itu dengan baik, yaitu mencapai tujuan yang diinginkan melalui pekerjaan itu, dengan efektif, aman, sehat, nyaman, dan efisien. Tidak hanya dalam hubungannya dengan a lat, ergonomi juga mencakup pengkajian interaksi antara manusia dengan unsur-unsur sistem kerja lain, yaitu bahan dan lingkungan, bahkan juga metode dan organisasi.

\section{Antropometri}

Menurut cara pengukurannya, antropometri dibagi atas dua bagian yaitu :

1. Antropometri statis, dimana pengukuran dilakukan pada tubuh manusia yang berada dalam posisidiam.

2. Antropometri dinamis, dimana dimensi tubuh diukur dalam berbagai posisi tubuh yang sedang bergerak, sehingga lebih kompleks dan lebih sulit diukur.

\section{Nordic Body Map}

Nordic body map adalah sistem pengukuran keluhan sakit pada tubuh yang dikenal dengan

musculoskeletal. Sebuah sistem muskulosk eletal (sistem gerak) adalah sistem organ yang memberikan manusia kemampuan untuk bergerak menggunakan $s$ istem otot dan rangka. Sistem muskuloskeletal menyediakan bentuk, dukungan, stabilitas, dan gerakan tubuh. Sistem rangka adalah suatu sistem organ yang memberikan dukungan fisik pada makhluk hidup. Sistem rangka umumnya dibagi menjadi tiga tipe: eksternal, internal, dan basis cairan (rangka hidrostatik), walaupun $\mathrm{s}$ istem rangka hidrostatik dapat pula dikelompokkan secara terpisah dari dua jenis la innya karena tidak adanya struktur penunjang.

\section{Uji Kecukupan Data}

Uji kecukupan data diperlukan untuk memastikan bahwa data yang telah dikumpulkan adalah cukup secara objektif. Idealnya pengukuran harus dilakukan dalam jumlah yang banyak, bahkan sampai jumlah yang tak terhingga agar data hasil pengukuran layak untuk digunakan. Adapun rumus yang digunakan adalah sebagai berikut :

$$
\mathrm{N}^{\prime}=\frac{k}{s}\left(\sqrt{\mathrm{N}}\left(\sum x^{2}\right)-\left(\sum x\right) 2\right)^{2}
$$

Dimana : N' = Jumlah data teoritis

$$
\begin{aligned}
\mathrm{k} & =\text { Tingkat Kepercayaan } \\
\mathrm{s} & =\text { Tingkat Ketelitian } \\
\sum x & =\text { Total data }
\end{aligned}
$$

\section{Uji Keseragaman Data}

Uji keseragaman data digunakan untuk memastikan bahwa yang terkumpul berasal dari sistem yang sama, maka dilakukan pengujian terhadap keseragaman data. Pengujian keseragaman data diperlukan untuk memisahkan data yang memiliki karasteristik yang berbeda. Adapun rumusnya adalah sebagai berikut :

$$
\begin{array}{r}
\mathrm{BKA}=\mathrm{X}+\mathrm{k}(\sigma) \\
\mathrm{BKB}=\mathrm{X}+\mathrm{k}(\sigma) \\
\sigma=\sqrt{\sum \frac{(x-x i)^{2}}{N-1}}
\end{array}
$$

Dimana : BKA = Batasan kendali atas

$$
\begin{aligned}
\mathrm{BKB} & =\text { Batas kendali bawah } \\
\sigma & =\text { Standart deviasi } \\
\mathrm{X} & =\text { Rata }- \text { rata } \\
\mathrm{Xi} & =\text { Rata }- \text { rata ke-i } \\
\mathrm{N} & =\text { Jumlah data }
\end{aligned}
$$

\section{REBA}

Rapid Entire Body Assesment (REBA) adalah sebuah metode dalam bidang ergonomic yang digunakan secara tepat dalam penilaian postur leher, punggung, pergelangan tangan, dan kaki seorang pekerja. Metode REBA telah mengikuti karakteristik yang telah dikembangkan untuk memberikan jawaban untuk keperluan mendapatkan yang bisa digunakan untuk 
mengukur aspek pembebanan fisik pekerja . Analisa dapat dibuat sebelum dan sesudah sebuah interfensi untuk mendemontrasikan resiko yang telah dihentikan dari sebuah cedera yang timbul. Hal ini memberikan kecepatan pada penilaian sistematis.

\section{Metodelogi Penelitian}

Adapun tahapan metode yang dilakukan dalam penelitian ini adalah sebagai berikut, yaitu :

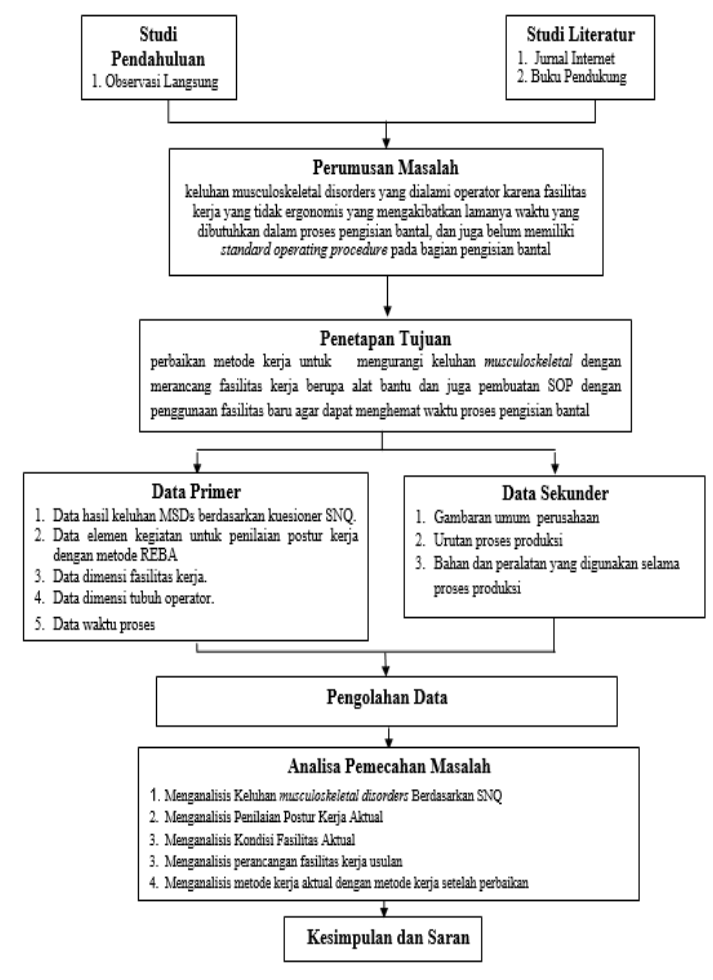

Gambar 1. Blok Diagram Penelitian

\section{Hasil Dan Pembahasan Data Hasil Keluhan MSDs}

Standard Nordic Questionare (SNQ) dibuat untuk mengetahui keluhan yang dialami oleh operator selama melakukan aktivitas pengisian bantal pada stasiun pengisian bantal. Pengumpulan data SNQ diberikan kepada enam orang operator pada stasiun pengisian bantal. Setiap operator yang mengisi kuesioner SNQ tersebut memiliki waktu kerja yang sama. Hasil rekapitulasi SNQ yang diperoleh dapat dilihat pada Tabel 1.

Tabel 1. Hasil Rekapitulasi SNQ Pekerja

\begin{tabular}{|c|c|c|c|c|c|c|c|c|c|c|c|c|c|c|c|c|c|c|c|c|c|c|c|c|}
\hline \multirow{2}{*}{ Operator } & \multicolumn{24}{|c|}{ No Dimensi Tubuh } \\
\hline & 0 & 1 & 2 & 3. & & 6 & & & 10 & 11 . & 1213 & 14 & & & 17 & & & 202 & 2122 & & 324 & 25 & & 27 \\
\hline 1 & 2 & 1 & 3 & 3.1 & 1 & 4 & 2 & 21 & 2 & 3 & 12 & 3 & 3 & 1 & 2 & $2:$ & 3 & $1:$ & & 3 & 2 & 2 & & \\
\hline 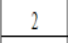 & 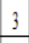 & 3 & 2 & 23 & 3 & & & 22 & 2 & 2 & $\begin{array}{l}32 \\
\end{array}$ & 3 & 2 & 4 & 3 & $2:$ & 2. & $2:$ & 23 & 3 & 2 & 2 & 2 & \\
\hline J & 2 & 2 & 1 & 3. & 1 & 1 & & 11 & 1 & 1 & 11 & 1 & 1 & 1 & 1 & 2. & 2. & $2:$ & 22 & 22 & 2 & 2 & 2 & - \\
\hline 4 & 2 & 2 & 2 & 22 & 2 & 2 & 2 & 22 & 2 & 2. & 22 & 2 & 2 & 2 & 2 & 3 & 3 & 3 & 33 & 3 & 3 & 3 & 3 & 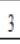 \\
\hline 5 & 1 & 2 & 1 & 1. & & & & 11 & 1 & 1 & 11 & 1 & 2 & 1 & 1 & 1 & 1 & 1 & 11 & 1 & 1 & 1 & 1 & \\
\hline 6 & & & & & & & & 1 & 2 & 2 & & & & & & & & & & & & & & \\
\hline
\end{tabular}

\section{Data Penilaian Postur Kerja}

Tabel 2. Data Penilaian Postur Kerja Pekerja

\begin{tabular}{|l|c|c|c|l|}
\hline \multirow{2}{*}{ Kegiatan } & \multicolumn{2}{|c|}{$\begin{array}{l}\text { Skor dan Level dari Penilaian } \\
\text { Postur Kerja dengan REBA }\end{array}$} & \multicolumn{2}{c|}{ Tindakan } \\
\cline { 2 - 5 } & Kiri & Kanan & \multicolumn{1}{c|}{ Kiri } & Kanan \\
\hline $\begin{array}{l}\text { Elemen kegiatan } \\
\text { menggulung serat } \\
\text { (Fiber) }\end{array}$ & 6 (sedang) & 6 (sedang) & $\begin{array}{l}\text { Perlu } \\
\text { perbaikan }\end{array}$ & $\begin{array}{l}\text { Perlu } \\
\text { perbaikan }\end{array}$ \\
\hline $\begin{array}{l}\text { Elemen kegiatan } \\
\text { menimbang serat } \\
\text { (fiber) }\end{array}$ & 2 (kecil) & 3 (kecil) & $\begin{array}{l}\text { Mungkin } \\
\text { diperlukan } \\
\text { perbaikan }\end{array}$ & $\begin{array}{l}\text { Mungkin } \\
\text { diperlukan } \\
\text { Perbaikan }\end{array}$ \\
\hline $\begin{array}{l}\text { Elemen kegiatan } \\
\text { memasukkan serat } \\
\text { (Fiber) kedalam } \\
\text { cetakan bantal } \\
\text { (operator 1) }\end{array}$ & 8 (tinggi) & 8 (tinggi) & $\begin{array}{l}\text { Segera } \\
\text { perbaikan }\end{array}$ & $\begin{array}{l}\text { Segera } \\
\text { perbaikan }\end{array}$ \\
\hline $\begin{array}{l}\text { Elemen kegiatan } \\
\text { memasukkan serat } \\
\text { (Fiber) kedalam } \\
\text { cetakan bantal } \\
\text { (operator 2) }\end{array}$ & 2 (kecil) & 2 (kecil) & $\begin{array}{l}\text { diperlukan } \\
\text { perbaikan }\end{array}$ & $\begin{array}{l}\text { Mungkin } \\
\text { diperlukan } \\
\text { perbaikan }\end{array}$ \\
\hline $\begin{array}{l}\text { Elemen kegiatan } \\
\text { melempar bantal yang } \\
\text { telah diisi serat (Fiber) }\end{array}$ & 4 (sedang) & 4 (sedang) & $\begin{array}{l}\text { Perlu } \\
\text { perbaikan }\end{array}$ & $\begin{array}{l}\text { Perlu } \\
\text { perbaikan }\end{array}$ \\
\hline
\end{tabular}

\section{Data Waktu Pengisian Bantal}

Dari pengamatan yang diperoleh secara langsung dengan menggunakan stop watch terhadap pekerjaan pengisian bantal, maka diperoleh waktu proses beberapa kali pengamatan untuk proses pengisian bantal yang dapat dilihat pada Tabel 3.

Tabel 3. Waktu Pengisian Bantal

\begin{tabular}{|c|c|}
\hline No & Waktu Proses \\
\hline 1 & 160 \\
\hline 2 & 162 \\
\hline 3 & 165 \\
\hline 4 & 163 \\
\hline 5 & 160 \\
\hline 6 & 162 \\
\hline 7 & 160 \\
\hline 8 & 162 \\
\hline 9 & 165 \\
\hline 10 & 160 \\
\hline
\end{tabular}

Tabel 4. Data Dimensi Pekerja yang digunakan dalam rancangan fasilitas kerja usulan

\begin{tabular}{|r|l|c|c|c|c|c|c|}
\hline \multirow{2}{*}{ No } & \multirow{2}{*}{ Dimensi Tubuh } & \multicolumn{7}{|c|}{ Operator } \\
\cline { 2 - 8 } & & $\mathbf{1}$ & $\mathbf{2}$ & $\mathbf{3}$ & $\mathbf{4}$ & $\mathbf{5}$ & $\mathbf{6}$ \\
\hline 1 & $\begin{array}{l}\text { Tinggi Duduk } \\
\text { Tegak (TDT) }\end{array}$ & 83,20 & 88,50 & 86,90 & 84,50 & 86,00 & 90,10 \\
\hline 2 & $\begin{array}{l}\text { Tinggi Bahu } \\
\text { Duduk (TBD) }\end{array}$ & 57,80 & 60,40 & 61,00 & 59,50 & 63,00 & 62,50 \\
\hline 3 & $\begin{array}{l}\text { Tinggi Siku } \\
\text { Duduk (TSD) }\end{array}$ & 19,50 & 22,30 & 18,40 & 24,00 & 21,00 & 25,80 \\
\hline 4 & $\begin{array}{l}\text { Tinggi Polipteal } \\
\text { (Tpo) }\end{array}$ & 38,00 & 40,10 & 41,50 & 38,20 & 37,20 & 40,30 \\
\hline 5 & $\begin{array}{l}\text { Pantat Polipteal } \\
\text { (PP) }\end{array}$ & 45,00 & 43,00 & 41,10 & 44,40 & 39,40 & 40,56 \\
\hline 6 & $\begin{array}{l}\text { Lebar Pinggul } \\
\text { (LP) }\end{array}$ & 32,00 & 31,60 & 33,10 & 34,00 & 33,80 & 35,15 \\
\hline 7 & Lebar Bahu (LB) & 42,00 & 45,00 & 41,80 & 43,60 & 40,80 & 41,20 \\
\hline
\end{tabular}




\section{Perancangan Fasilitas Kerja Usulan}

Adapun aktivitas keseluruhan dari penggunaan fasilitas kerja berupa kursi kerja dan meja luncur dapat dilihat pada Gambar 2.

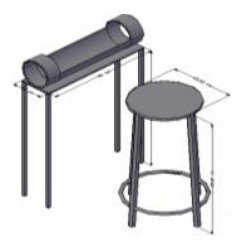

(a)

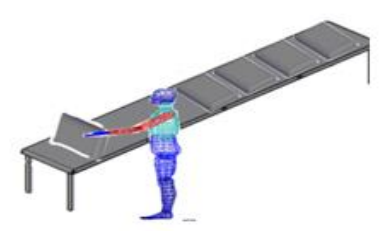

(b)
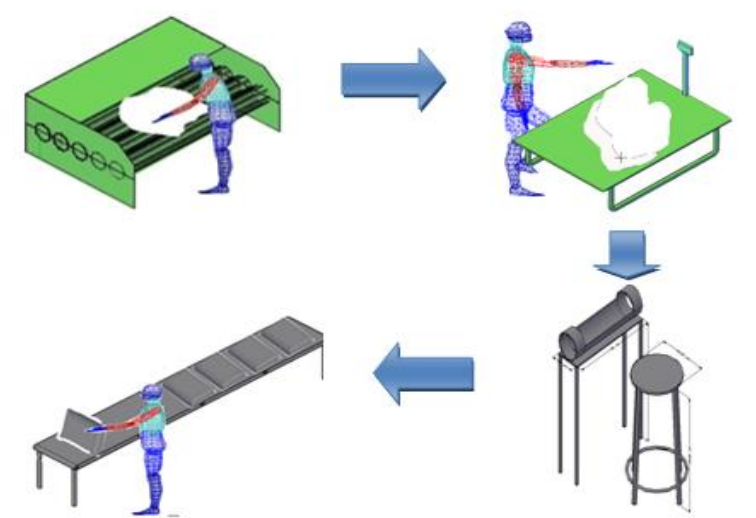

(c)

Gambar 2. (a) Fasilitas kerja usulan ( kursi kerja) setelah digunakan operator

(b) Fasilitas kerja usulan ( meja luncur) setelah digunakan operator

(c) Aktivitas Kerja Keseluruhan (Usulan)

\section{Metode Kerja Aktual dan Metode Kerja Baru}

Perbandingan Metode Kerja Aktual dan Metode Kerja dapat dilihat pada tabel 5 .

Tabel 5. Perbandingan Metode Kerja Aktual dan Metode Kerja Baru

\begin{tabular}{|c|l|l|}
\hline No. & \multicolumn{1}{|c|}{ Prosedur kerja Lama } & \multicolumn{1}{c|}{ Prosedur Kerja Baru } \\
\hline 1 & $\begin{array}{l}\text { Operator membungkuk pada saat } \\
\text { menggulung serat (fiber) dengan posisi } \\
\text { berdiri }\end{array}$ & $\begin{array}{l}\text { Operator membungkuk pada saat } \\
\text { menggulung serat (fiber) dengan } \\
\text { posisi berdiri }\end{array}$ \\
\hline 2 & $\begin{array}{l}\text { Operator berjalan untuk menimbang } \\
\text { serat (fiber) dengan posisi berdiri }\end{array}$ & $\begin{array}{l}\text { Operator berjalan untuk menimbang } \\
\text { serat (fiber) dengan posisi berdiri }\end{array}$ \\
\hline 3 & $\begin{array}{l}\text { Operator memasukkan serat (fiber) } \\
\text { kedalam cetakan bantal dengan posisi } \\
\text { berdiri dengan punggung } \\
\text { membungkuk }\end{array}$ & $\begin{array}{l}\text { Operator memasukkan serat (fiber) } \\
\text { kedalam cetakan bantal dengan posisi } \\
\text { berdiri dengan menggunakan fasilitas } \\
\text { kerja berupa kursi posisi berdiri }\end{array}$ \\
\hline 4 & $\begin{array}{l}\text { Operator melempar bantal kestasiun } \\
\text { penjahitan dengan postur kerja yang } \\
\text { kurang ergonomis }\end{array}$ & $\begin{array}{l}\text { Operator meletakkan bantal keatas } \\
\text { meja luncur ke stasiun penjahitan }\end{array}$ \\
\hline
\end{tabular}

\section{Perancangan Standard Operation Procedure}

Berikut ini Standard operating procedure berdasarkan metode kerja yang baru:

a. Operator menggulung serat (fiber)

b. Operator menimbang serat (fiber)

c. Operator memasukkan serat (fiber) kedalam cetakan bantal dengan menggunakan kursi kerja posisi berdiri Operator meletakkan bantal yang telah diisi diatas meja luncur menuju stasiun penjahitan

\section{Kesimpulan}

Hasil pengolahan data dan analisis pembahasan memberikan beberapa kesimpulan sebagai berikut:

1. Perbaikan alat fasilitas kerja disesuaikan dimensi antropometri tubuh operator. Adapun dimensi antropometri tubuh operator yang digunakan adalah tinggi siku duduk, lebar bahu, tinggi polipteal, tinggi bahu duduk, pantat polipteal, lebar pinggul dan tinggi duduk tegak

2. Untuk mereduksi keluhan MSDs yang diperoleh dari hasil penilaian SNQ dan postur kerja, maka dibuat suatu fasilitas kerja usulan berupa kursi kerja posisi berdiri dan meja luncur.

3. SOP baru yang dihasilkan dapat memberikan pembagian pekerjaan yang merata untuk masingmasing pekerja sehingga tidak terjadi pembagian pekerjaan yang tidak sesuai.

4. Dari hasil analisis metode kerja baru maka dapat dilakukan proses pengisian bantal sebanyak 25 kali pengulangan per jam, setelah dilakukan perbaikan metode kerja dapat dilaksanakan 26 dan 27 kali pengulangan.

\section{Daftar Pustaka}

[1 ] Banerjee and Somnath G. A Study On The Prevalence Of Upper Extremity Repetitive Strain Injuries Among The Handloom Weavers Of West Bengal. 2003

[2] Barnes, Ralph M. Motion and Time Study Design Measurement of Work. 1974.

[3] Highnett, Sue and Mc Atamney, Lynn. Rapid Entire Body Assessment (REBA); Applied Ergonomics. 2001.

[4 ]Iridiastadi, H., (2014), Ergonomi : SuatuPengantar, PT Remaja Rosdakarya Offset.

[5] Nuragustin. D, dan Muslim. E. Perancangan Metode dan Tempat Kerja Bagian Packing Produk Bumbu A di PT XYZ Dengan Menerapkan Prinsip Ergonomi.

[6]Sinulingga, Sukaria. Metode Penelitian. Edisi Pertama. USU Press. Medan. 2011.

[7] Sutalaksana, I.Z, dkk. Teknik Tata Cara Kerja. Bandung: ITB. 1979.

[8 ]Tarwaka, Dkk. 2004. "Ergonomi untuk Keselamatan, Kesehatan Kerja dan Produktivitas". Surakarta : Uniba Pres

[9] Wignjosoebroto, Sritomo. Ergonomi Studi Gerak dan Waktu. Edisi Pertama. Cetakan Keempat. Penerbit Guna Widya. Surabaya. 1995. 